DOI https://doi.org/10.30525/978-9934-26-046-9-28

\title{
OPTIMIZATION OF SEARCHING FOR MOVING TARGETS OF A MULTIFUNCTIONAL RADAR STATION
}

\author{
Piskunov S. M. \\ Candidate of Technical Sciences, \\ Head of Department of Armament of the Air Defense Forces \\ of the Land Forces \\ Ivan Kozhedub Kharkiv National Air Force University \\ Romenskyi D. S. \\ Cadet \\ Ivan Kozhedub Kharkiv National Air Force University \\ Budur M. I. \\ Cadet \\ Ivan Kozhedub Kharkiv National Air Force University \\ Kharkiv, Ukraine
}

A method of optimizing the process of searching for an unknown number of moving targets in conditions of stochastic uncertainty is proposed, which allows to significantly reduce the average time of their search by a multifunctional radar device equipped with a digital antenna array [8; 10]. More effective is the optimal managed search, in which the order of viewing different directions is determined in the search process depending on the results of already performed views. If the time is sampled and the sampling step is taken as the search step, the controlled search method, in which the average target search time is minimal, will be as follows: after each subsequent search step of a given duration during which the corresponding direction is viewed, a posteriori probabilities in each of the directions and in the next stage the direction for which this probability is the greatest is looked through. One of the important areas of further improvement of radar technology is the transition to antenna arrays with digital beamforming based on adaptive signal processing directly in the elements of the digital antenna array (CAR). The main advantage of CAR is the solution of the problem of detection and support of a large number of targets in the conditions of intensive radio counteraction due to the possibility of forming several independently controlled antenna patterns in the 
reception mode. For these systems it is important to create effective search methods, one of which is proposed in this article. The radar inspection area in which the target is moving is divided into cells. The target is in each cell for a random period of time and then moves to another. The probability of transition from one cell to another is determined by the probability law $[1 ; 2]$.

The following main factors are taken into account: the size of the working area, determining the coordinates and accuracy of their measurement, the resolution of the radar in range, radial speed and angular coordinates, the required time of one inspection of the working area, the possibility of target in different elements of the inspection area, search method. Radar quality indicators such as the average time spent on target detection (average time of undetected target existence) and the average time between adjacent false detections (average frequency of false alarms) significantly depend on the method of inspection. Inspection of the elements of the work area is carried out either sequentially over time or simultaneously. In accordance with this, there are radar systems of sequential and simultaneous inspection. At the same time, the target signals are received and processed as soon as the target appears in the work area. Therefore, such systems are also called without search engines. The advantage of simultaneous inspection systems is the high rate of obtaining radar information about the targets in the work area, the disadvantage is the great complexity compared to sequential inspection systems. Inspection of the working area at a distance is carried out in the process of propagation of the radio signal with a final speed to the target and back. No special operations are required to perform such an inspection [6-7]. Radar signals corresponding to the various elements of the range are received at the input of the radar receiver sequentially in time. However, due to the high speed of dissemination of radio waves, the inspection of all elements of distance discrimination is carried out over a short period of time - almost simultaneously, even at very short range radar. Synchronous reception of signals corresponding to different elements of distance distinction is associated with the need to use a channel processing device. In order to simplify the equipment, a tunable receiver with a smaller number of processing channels can be used instead of the optimal channel processing device. In this case, signals corresponding only to the elements of the range distinction are processed simultaneously, and the inspection of all elements is performed sequentially in time by adjusting the receiver. At consecutive inspection on distance there are energy losses. The inspection of the working area by angular coordinates is simultaneous if the beam or several beams of the radar in the statistical position 
completely overlap this area. At simultaneous inspection the number of elements of distinction on a direction will be equal to number of beams of a radar $[11 ; 16]$.

If one or more radar beams in the static position do not completely cover the working area, a sequential inspection in the direction by expanding the beam within the entire area (scanning) is applied. Sequential inspection in the direction is not associated with any energy losses and is widely used in radars for various purposes. The main advantage of this method is the simplicity of its implementation: one scanning beam requires a singlechannel receiver, while a simultaneous inspection of the number of channels of the receiver is equal to the number of used beams. The radar surveillance area in which the target is moving is divided into cells. The target is in each cell for a random period of time and then moved to another. The probability of transition from one cell to another is given by probability law $[3 ; 5]$.

\section{References:}

1. Kisilov S., Piskunov S., Filippenkov O., Shevchenko A. Countering rocket artillery and mortar shelling - promising direction of air defense development of the Ground Forces. Systems of Arms and Military Equipment. 2017. № 4 (52). Pp. 17-27.

2. Drobaha G., Piskunov S., Tikhonov I. Development of tactics of action of means of wind attack in local conflicts of the XXI century. Systems of Arms and Military Equipment. 2010. № 1 (21). Pp. 6-10.

3. Hellman O. Introduction to the theory of optimal search. Moscow. 1985. $248 \mathrm{p}$.

4. Koopman B. The theory of search. Operation Research. 1957. № 5. Pp. 613-626.

5. Korotya A., Adamovsky O., Piskunov S. The method of minimizing the time of searching for air targets in survey radar stations. Science and Technology of the Air Force of Ukraine. 2014. № 2 (15). Pp. 107-108.

6. Chikriy A., Klimenko E. Discrete search problem with a priori awareness. Cybernetics and exc. technique. Kiev. 1988. № 79. Pp. 28-33.

7. Sira S.P. Advances in Waveform-Agile Sensing for Tracking. Synthesis Lectures on Algorithms and Software in Engineering. Lecture 2. New York: Morgan \& Claypool Publishers series, 2009. 83 p.

8. Haug A.S. Bayesian Estimation and Tracking. A Practical Guide. New York: Published by John Wiley \& Sons, 2012. 397 p.

9. Kuzmin S. Digital radar. Introduction to the theory. Kyiv .: KViTs, 2000. 428 p. 
10. Piskunov S., Reshetnik V., Filonenko S., Titova E. Optimization of the observation control process when detecting air targets in a multifunctional radar station. Radio electronics and computer science. 1998. №1 (2). Pp. 82-84.

11. Iasechko M., Tymochko O., Shapran Y., Trofymenko I., Maksiuta D., Sytnyk Y. Loss definition of charged particles in the discharge gap of the opening of the box-screens during the formation of a highly conductive channel. IJATCSE. 2019. № 8 (1.3). Pp. 1-9.

12. Iasechko M., Larin V., Maksiuta D., Ochkurenko O., Samsonov Y., Lyashenko H., Zinchenko A. Influence of ionization source onto macroscopic parameters of the air media in the holes in cops-screensof radio electronic means. APRN Journal of Engineering and Applied Sciences. 2019. № 14 (20). Pp. 3566-3571.

13. Iasechko M., Turinskyi O., Burdin M., Larin V., Gnusov Y., Ikaev D., Borysenko V., Manoylo V. Protection of board radioelectronic equipment from the destructive powerful electromagnetic radiation with the use of natural technologies. IJETER. 2019. № 7 (11). Pp. 542-548.

14. Iasechko M., Sotnikov O., Syrotenko A., Larin V., Iasechko S., Ochkurenko O., Volkov A. Model of Combined Solid Plasma Material for the Protection of Radio-Electronic Means of Optical and Radio Radiation. IJATCSE. 2019. № 8 (4). pp. 1241 - 1247.

15. Iasechko M., Sotnikov O., Larin V., Ochkurenko O., Maksiuta D. The model of a medium for creation of electric hermetic screens of the radio electronic means. IJATCSE. 2019. № 8(2). Pp. 300-304.

16. Iasechko M., Turinskyi O., Larin V., Prokopenko T., Kolmohorov O., Salash O., Tarshyn V. The Investigation of the Impulse Evolution of the Radio-Frequency and Optical Radiation During the Interaction With the Solid-State Plasma Media On Radioisotope and Hexaferrite Inclusions. IJETER. 2020. № 8(4). Pp. 1333-1337. 